\title{
El papel del Patronato de Misiones Pedagógicas como divulgador de la cultura musical en la España de la II República*
}

Recibido: julio 7 de 2017 | Aceptado: febrero 23 de 2018

DOI: 10.17230/co-herencia.15.29.13

\author{
Narciso José López García** \\ narcisojose.lopez@uclm.es \\ María del Valle De Moya Martínez*** \\ mariavallede.moya@uclm.es \\ Raquel Bravo Marín ${ }^{* * * *}$ \\ raquel.bravo@uclm.es
}

Resumen El Patronato de Misiones Pedagógicas desarrolló una importante labor de recuperación y difusión de la cultura musical, especialmente del folklore musical español, en los primeros años de la II República española, al poner en marcha un servicio de música y un coro que se encargaron de acercar diferentes estilos y géneros musicales a los habitantes de las zonas rurales más deprimidas. En este artículo se presenta un estudio documental sobre el trabajo llevado a cabo por los integrantes del coro y por las personas que se encargaron de custodiar los recursos musicales cedidos por el Patronato y de programar las diferentes actividades musicales en los municipios que gozaron de dichos recursos. A su vez, se recogen diversos testimonios que dan fe del cometido realizado por esta institución y del impacto cultural y musical que supuso en los habitantes de las localidades donde se desarrollaron las diferentes actividades misionales.

\section{Palabras clave:}

Misiones Pedagógicas, cultura musical, educación musical, II República española.

\begin{abstract}
Una versión anterior de este artículo fue presentada en el II Encuentro del Grupo de trabajo Música y Artes Escénicas de la SEDEM: Identidades a escena (II): canción y baile en la II República, 9 y 10 de febrero de 2017, en la Escuela Superior de Canto de Madrid (España).

** Profesor del Departamento de Didáctica de la Expresión Musical-Grupo LabinTic. Facultad de Educación de Albacete-Universidad de Castilla-La Mancha, España ORCID ID: 0000-0002-5665-5263.
\end{abstract}


The role of the Patronage of Pedagogical Missions as a promoter of musical culture in Spain during the Second Republic

\begin{abstract}
The Patronage of Pedagogical Missions played an important role in the recovery and dissemination of musical culture, particularly Spanish musical folklore,

in the early years of the Second Spanish Republic, by launching a musical and choir service that was in charge of bringing a variety of music styles and genres to the inhabitants of the most deprived rural areas. In this paper a thorough documentary study was carried out on the work performed by the choir members and by the people who were responsible for guarding the musical resources ceded by the Patronage as well as for programming the different musical activities in the municipalities that benefitted from such resources. In turn, several testimonies gathered attest to the task done by this institution as well as to the cultural and musical impact it had on the inhabitants of the towns where the different missionary activities were performed.
\end{abstract}

\section{Keywords:}

Pedagogical Missions, musical culture, musical education, Second Spanish Republic.
${ }^{* * *}$ Profesora del Departamento de Didáctica de la Expresión Musical-Grupo LabinTic. Facultad de Educación de Albacete-Universidad de Castilla-La Mancha, España. ORCID ID: 0000-0003-4701-4963

***** Profesora del Departamento de Didáctica de la Expresión Musical-Facultad de Educación de Albacete, Universidad de Castilla-La Mancha, España. Miembro del grupo LabinTic. ORCID ID: 0000-0001$5809-7739$

Las primeras referencias existentes sobre las Misiones Pedagógicas datan de 1881, año en que Francisco Giner de los Ríos y Manuel Bartolomé Cossío solicitaron al Ministerio de Fomento la creación de misiones ambulantes con las que llevar maestros cualificados a las poblaciones rurales más deprimidas de la geografía española. Pero no será hasta 1907 cuando, según Real Decreto de 10 de enero, se establezca la creación de una Junta específica para el fomento de la educación nacional, siendo una de sus muchas actividades la puesta en marcha de misiones y conferencias pedagógicas. Sin embargo, la difícil situación económica del país sumada a las necesidades urgentes de la enseñanza (pago de sueldos de los maestros, reposición de materiales, mobiliario deficiente y obsoleto, restauración de edificios escolares ruinosos), así como los continuos cambios políticos -y en consecuencia, las constantes modificaciones legislativas- dificultaron la labor de este servicio durante casi treinta años (Canes, 1993).

Fue en el año de 1931, ya proclamada la II República Española, cuando se creó el Patronato de Misiones Pedagógicas (según Decreto de 29 de mayo), con la finalidad de: 
llevar a las gentes, con preferencia a las que habitan en localidades rurales, el aliento del progreso y los medios de participar en él, en sus estímulos morales y en los ejemplos del avance universal, de modo que los pueblos todos de España, aun los más apartados, participen en las ventajas y goces nobles reservados hoy a los centros urbanos. (Decreto de 29 de mayo, 1931, p. 1033)

Además, ponía de manifiesto la profunda preocupación del gobierno republicano por tender puentes de unión entre el mundo rural y el mundo urbano para favorecer, con ello, la educación del pueblo (Puelles, 1991) y eliminar, en lo posible, las diferencias evidentes por medio de la cultura.

En esta misma línea, Moreno (2017, p. 83) señala que:

Las Misiones Pedagógicas nacían como un medio, a través de la educación no formal y la difusión cultural, para favorecer la equidad, la justicia social, la modernización, la democratización y la noción de ciudadanía, acabar con el aislamiento del mundo rural y favorecer la comunicación entre las ciudades y las aldeas, así como apoyar y contribuir a la mejora y al reconocimiento social de la labor del maestro y la escuela de la España más olvidada, la España rural.

El propio Manuel Bartolomé Cossío afirmaría que el origen de la creación del Patronato hay que buscarlo en la diferencia abismal, en lo intelectual y en lo económico, existente entre el campo y la ciudad, además del derecho de los aldeanos a disfrutar de la cultura tal y como podían hacerlo los habitantes de las ciudades (Canes, 1993). Con esta finalidad se pusieron en marcha una serie de actividades culturales entre las que se incluían audiciones de música coral, formación de pequeñas orquestas, audiciones radiofónicas, audiciones de discos seleccionados e interpretación coral de repertorio del folklore español. De esta manera, el Patronato apostaba por impulsar el valor de la cultura y de la educación y difusión musical como parte fundamental de su idea para potenciar la educación ciudadana (Ocaña, 2006).

De esta manera, el gobierno republicano mostraba la profunda creencia de que "solo con educación y cultura se podrían cambiar las estructuras sociales del país” (Martín Ruano, 2015, p. 377) y confiaba a algunos de los intelectuales más notables de la España del siglo XX (Antonio Machado, Pedro Salinas, Federico García Lorca, Alejandro 
Casona, María Zambrano, José Val de Omar, Ramón Gaya o Carmen Conde, entre otros) y a un buen número de estudiantes y profesores, todos ellos voluntarios, la empresa de transmitir a todos los rincones de la geografía española los tres pilares básicos en los que se debía fundamentar la labor educativa de un Estado democrático: gratuidad, obligatoriedad y laicidad, asumiendo con ello que el sistema nacional de educación no se centraba solo en la escuela, y presentando, fuera de este ámbito, una experiencia paralela de educación popular (Hontañón y Pericacho, 2015).

\section{La cultura musical española anterior a la II República}

El contexto musical anterior a la proclamación de la II República ofrecía un panorama centralizado, casi en exclusiva, en las grandes ciudades y en las poblaciones con mayor número de habitantes y con recursos económicos suficientes para programar agendas culturales, artísticas y musicales. Cabe destacar, sin embargo, la existencia de un importante movimiento "bandístico" que había permitido el acceso al repertorio musical culto y popular a un sector de población perteneciente a estratos sociales más desfavorecidos, ya fuera como componentes de las bandas o como meros espectadores y receptores de las actividades artístico-musicales llevadas a cabo por estas agrupaciones. Sobre este asunto, Ayala (2013) señala que entre 1875 y 1931 se fomentaría la municipalización de las bandas civiles y que en 1935 había registradas 510 bandas civiles de música, número que aumentaría si tenemos en cuenta las agrupaciones dirigidas por músicos que no pertenecían al cuerpo de directores de bandas y todas aquellas de carácter privado o particular; es decir, prácticamente todas las capitales de provincias y un buen número de municipios distribuidos por toda la geografía española tenían, al menos, una banda de música.

Por otro lado, el Conservatorio de Música y Declamación de Madrid, que abriría sus puertas en 1830, recogía a los músicos y estudiantes de música más destacados de la España de la época. Además, en 1940, los Conservatorios de Córdoba, Málaga, Murcia, Sevilla, Valencia, Bilbao, Zaragoza, Tenerife, La Coruña, Cádiz, Salamanca, Oviedo, Baleares, Cartagena, Ceuta, San Sebastián, 
Santander, Vitoria, Valladolid, y Barcelona, serían declarados Conservatorios Profesionales, con validez académica y, en muchos casos, con dotaciones económicas generales o especiales, como compensación a su trayectoria educativo-musical desarrollada, fundamentalmente, durante los primeros años del recién estrenado siglo XX.

Con respecto al mundo de la danza, Calvo y León (2011) nos recuerdan que tanto Madrid como Barcelona contaban con escuelas de danza clásica y el baile flamenco vivía su primera edad de oro (1869-1929). Por otro lado, los ballets rusos habían actuado en Madrid (1915) y en Barcelona (1917), siendo éste el principal detonante de la puesta en marcha de las temporadas de ballet del Liceo.

En estos años previos a la II República encontramos, también, una proliferación de las sociedades corales y de los orfeones que, como señala Casares (1999), tendrán un corte cercano a los cánones nacionalistas y a la estética romántica, siendo una constante en ellos la invocación al canto popular puramente español. Además, en los años 20 se vivirá un enorme interés por la relación entre las diversas artes, aspecto que se verá reflejado en la comunicación fluida entre músicos y poetas que será especialmente fructífera. Esto se debe, fundamentalmente, a las buenas relaciones existentes entre los compositores y los literatos de la Generación del 27 que, tanto unos como otros, se verán fuertemente identificados con el movimiento cultural en el que estarán inmersos. En este punto, cabe destacar el importantísimo papel de Óscar Esplá por mostrar a la sociedad de la época que el cliché del compositor como hombre falto de cultura e insensible a todo lo que no estuviera relacionado con la música era injusto e incierto, abriendo el camino al nuevo arquetipo del compositor como "auténtico intelectual" (Gil, 2007).

Por último, hay que resaltar la existencia de una importante red de teatros -con los de Madrid, Barcelona, Granada, Cádiz, Sevilla y Valencia entre los más destacados- con programaciones fijas centradas, casi en exclusiva, en ópera, zarzuela y funciones líricas (Marco, 1998), así como el trabajo del Grupo de los Ocho de Madrid y su homónimo de Barcelona, que configurarán un panorama musical que servirá de columna vertebral para la nueva concepción musical y educativo-musical que se vivirá en los años posteriores, principalmente en el primer bienio republicano (1931-1933). 


\section{Actividades musicales programadas por el Patronato de Misiones Pedagógicas}

Hasta 1931, el Estado apenas había intervenido en el desarrollo de la música en España. Las orquestas, las sociedades corales y las sociedades filarmónicas eran privadas y las bandas civiles tenían un marcado carácter "municipalista". Aun así, el panorama musical descrito anteriormente hará que la sociedad española reaccione y comience a tomar conciencia de la importancia de la música y del hecho musical como parte fundamental e indispensable de la cultura del país (Gil, 2007). El 14 de abril de este año se proclamaba la II República y el nuevo gobierno dejaba clara desde el primer momento su profunda preocupación por la educación y la cultura y por llevarlas a la totalidad del pueblo español. Nacía, así, el Patronato de Misiones Pedagógicas con la firme intención de convertirse en una escuela ambulante que iría de pueblo en pueblo dirigiendo su labor a las gentes más pobres, más escondidas, más abandonadas, llevando proyectores, gramófonos, libros y otros servicios que acercarían la cultura a la población rural (Tapia, 2006). Esta institución estaba compuesta por una Comisión Central presidida por Manuel Bartolomé Cossío, por colaboradores permanentes y delegados y comisiones provinciales.

La acción de las Misiones abarcaba tres aspectos:

1. El fomento de la cultura general a través de la creación de bibliotecas fijas y circulantes, proyecciones cinematográficas, representaciones teatrales [...], conciertos, un museo circulante, etc.

2. La orientación pedagógica a los maestros de escuelas rurales.

3. La educación ciudadana necesaria para hacer comprensibles los principios de un gobierno democrático a través de charlas y reuniones públicas. (Gimeno, 2011, p.167)

Y las propuestas de zonas "misionables" tenían que estar avaladas por las inspecciones de primera enseñanza, por las comisiones provinciales o locales, por miembros del Patronato o por particulares de solvencia social (Patronato de Misiones Pedagógicas, 1934) que hacían llegar a la Comisión Central un expediente con información de la localidad, sus condiciones, oportunidad y posible eficacia de la actuación, así como datos económicos, culturales, sociales y geográficos para su montaje. 
El programa de actividades culturales incluía carteles anunciadores de los actos y el transporte del material necesario para poner en práctica la misión, quedando ésta estructurada, por lo general, del siguiente modo:

- Biblioteca fija y circulante.

- Cine y proyecciones fijas.

- Museo circulante.

- Coro y teatro del pueblo.

- El retablo de fantoches (guiñol).

- Cursos para maestros.

- Servicio de música.

El Coro y el Servicio de Música eran las dos actividades propiamente musicales del programa supervisadas directamente por Óscar Esplá, miembro de la Comisión Central, y programadas y llevadas a cabo por Eduardo Martínez Torner y Pablo de Andrés Cobos, todos ellos grandes personalidades del siglo XX español del momento.

\section{El papel del Coro de estudiantes en las Misiones Pedagógicas}

El Coro estaba integrado por unos cincuenta estudiantes universitarios y de Escuelas Normales (normalistas) dirigidos personalmente por Eduardo Martínez Torner, quien se encargaría de buscar, seleccionar y armonizar el repertorio basado, fundamentalmente, en canciones del folklore español: romances, cantigas, serranillas y otro tipo de piezas que el público pudiera reconocer con facilidad y los asumiera como cantos propios (Dennis, 2011). Esto suponía una importante labor de recuperación y difusión de la música tradicional española que se acompañaba de unas cuartillas que se repartían entre los lugareños con las letras de los temas a interpretar y, en ocasiones, con su transcripción musical.

El repertorio estaba formado por unas veinticinco piezas divididas en dos grupos: por un lado, las pertenecientes al folklore de carácter popular y, por otro, las procedentes de los cancioneros, romances y villancicos de los siglos XV y XVI. Los títulos de algunas de ellas eran: "El pañuelo a la moda" (Asturias), "Al monte voy por rama" (León), "En Samir de los Caños" (Zamora), "Las estrellas corren, 
corren" (Segovia y Salamanca), "Más vale trocar" (Juan del Encina), "El romance del conde Sol", "La loba parda", "El pastor desesperado", "La Condesita", "Misa de amor", canciones de baile de Zamora, cantos de boda de Salamanca y seguidillas manchegas y extremeñas, entre otros temas. Generalmente, las canciones populares y los recitados se interpretaban en los intermedios de las escenificaciones aunque, en ocasiones, la música y el canto se integraban dentro de las representaciones teatrales.

Sobre la selección del repertorio, Sánchez de Andrés (2006, s. p.) señala que:

Esta selección de obras respondía a un planteamiento pedagógico bien definido: comenzar el trabajo con la población rural a partir de su propio bagaje cultural. Nada más cercano a los aldeanos que las canciones populares y el recitado de romances, muchos de los cuales aún conservaban en su memoria. De este modo, los misioneros establecían un vínculo afectivo natural y directo con la población visitada y estimulaban la revitalización, o incluso la recuperación, del folclore popular, exaltando la expresión artística nacional -con todos sus valores patrióticos y culturales- frente a la influencia de otros repertorios foráneos de inferior calidad.

La primera actuación del Coro se llevó a cabo en Esquivias (Toledo), el 15 de mayo de 1932, y su radio de acción se extendió a un total de 286 pueblos de las provincias de Ávila, Badajoz, Cáceres, Ciudad Real, Cuenca, Guadalajara, Madrid, Salamanca, Segovia, Soria, Toledo, Valladolid, Zamora y Zaragoza (ver imágenes 1 y 2). Además, cuando las condiciones meteorológicas o geográficas no permitían viajar, sus integrantes se reunían para cantar en las cárceles y asilos de Madrid manteniendo viva la finalidad humanitaria de la educación en entornos desfavorecidos social, económica y culturalmente.

En 1934, el Coro llegó a grabar una serie de canciones populares en discos de pizarra. Estos ejemplares originales fueron presentados en la exposición sobre las Misiones Pedagógicas organizada por la Sociedad Estatal de Conmemoraciones Culturales, la Residencia de Estudiantes y la Fundación Giner de los Ríos en diciembre de 2006, celebrando los 75 años de la creación del Patronato. Además, la Sociedad Estatal de Conmemoraciones Culturales y la Residencia de Estudiantes publicaron un catálogo para el evento, 
Las Misiones Pedagógicas. 1931-1936 (2006), en el que se recogen fotografías, diferentes ensayos sobre el Patronato y sus servicios, la relación de participantes y colaboradores en las Misiones y de localidades misionadas y la relación de obras y documentos que formaron parte de la exposición. El catálogo se completa con un CD que recopila las siete canciones interpretadas por los Coros de las Misiones Pedagógicas grabadas en estos antiguos discos de pizarra en el mismo orden y, siguiendo la tradición de las Misiones, con la transcripción de los textos de las obras contenidas.

Los temas que componen la grabación digital son:

- "El pañuelo a la moda".

- "En Samir de los Caños".

- "Al monte voy por rama".

- "Las estrellas corren, corren".

- "Romance del conde Olinos".

- "Más vale trocar".

- "Romance del conde Sol".

\section{ACTUACIONES DE TEATRO Y CORO}

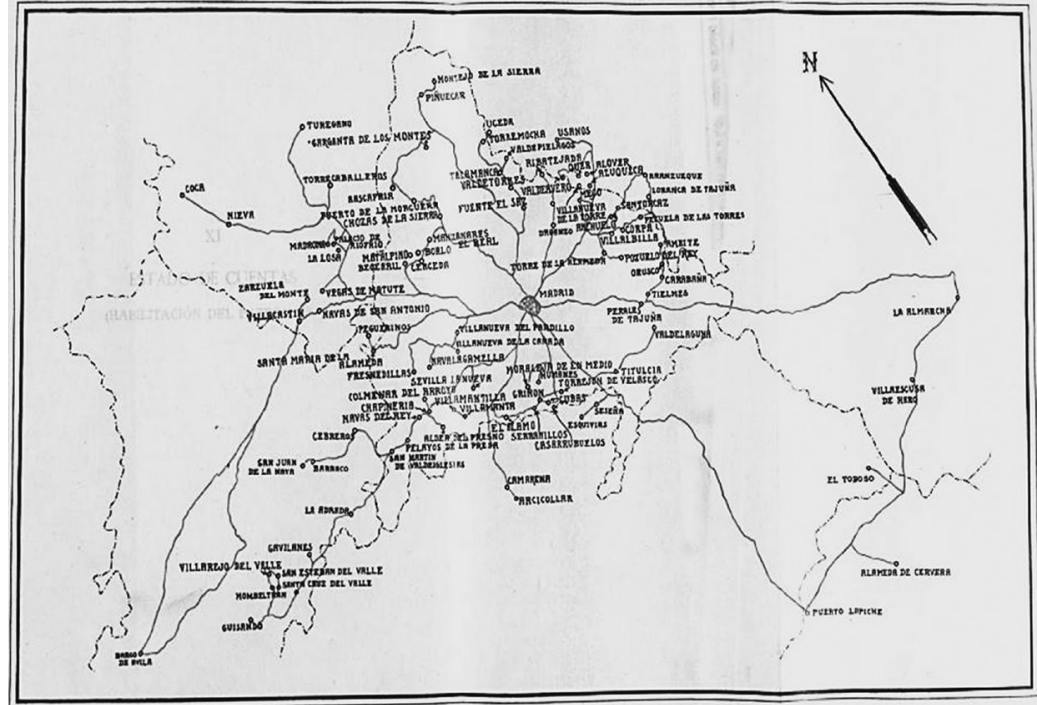

Imagen 1. Localidades en las que actuó el Coro de las Misiones Pedagógicas en los años 1932 y 1933.

Fuente: Patronato de Misiones Pedagógicas (1934, p. 145). 


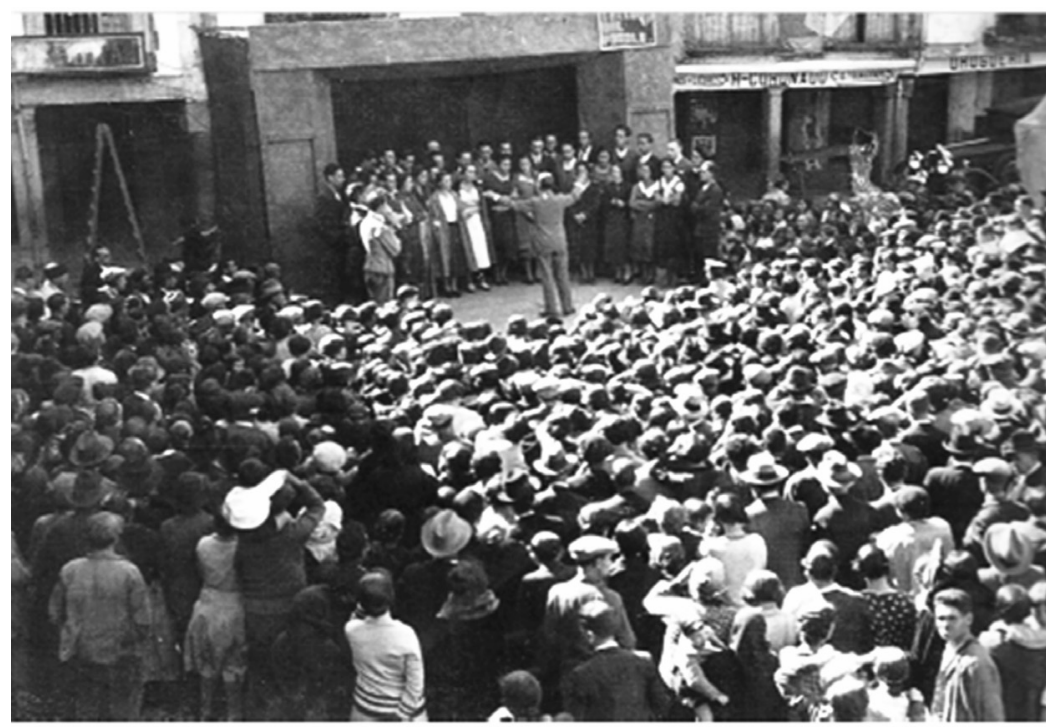

Imagen 2. Actuación del Coro en la plaza de un pueblo bajo la dirección de Martínez Torner. Fuente: Otero y García (2006, p. 432).

Estas antiguas grabaciones, aunque de baja calidad sonora, muestran la importantísima labor de los componentes de este Coro formado por aficionados y de su director, destacando por el cuidado y la excelencia de las interpretaciones. Esto, sin duda, tuvo un efecto impactante para los receptores fundamentalmente por tres aspectos:

- En primer lugar porque, en la inmensa mayoría de los casos, era la primera vez que escuchaban a una agrupación coral.

- Por otro lado, los integrantes del Coro demostraban una implicación, un trabajo previo y un respeto por lo que hacían y por el público al que iban dirigidas sus actuaciones que impactaba muy positivamente en los oyentes.

- Por último, la selección del repertorio aunaba a misioneros y "misionados" en una misma vivencia real y compartida que, hasta ese momento, era impensable para muchos de los asistentes.

Sobre este último aspecto, Carmen Caamaño (citada en Tapia, 2006), misionera e integrante del Coro, advierte lo siguiente:

¿De qué mundo vienen estas personas? Éramos tan lejos de su mundo, que parecía que venías de otras galaxias, de sitios que ellos no podían 
entrar en su imaginación que existieran. Ni cómo vestíamos, ni cómo llevábamos para comer, ni cómo hablábamos [...] Éramos otra cosa. Tampoco éramos los titiriteros que van por los pueblos. Había otra relación, era otra cosa. Era como si algo, de pronto, que no se puede creer, llegara a ellos y dijera: Pues sí, creedlo, que estamos aquí y venimos a ayudaros.

El primer volumen de las Memorias del Patronato, publicado en 1934, recoge un buen número de testimonios que dan fe de la importancia que tuvo este servicio de Coro del pueblo. Uno de estos ejemplos, quizás el más llamativo, lo encontramos en el diario de las misiones que se realizaron en La Cuesta y el Carrascal (Segovia) en 1932. En estos apuntes, escritos por uno de los miembros de la misión, podemos leer:

Las canciones populares gustaban todas, entusiasmaban algunas y quisieron oír toda la noche las canciones populares antiguas de Lorca. Hicimos entre todos lo que pudimos por hacerles gustar la buena música y comprendimos que tampoco para esto basta con quince días [...] Toda la música popular les encantaba, más la canción y mucho más lo segoviano de Marazuela. ${ }^{1}$ Todo esto removía los posos del alma, renovando las alegrías de la mocedad [...] Terminada la sesión hubo viejecillos, media docena, que recordaron canciones ya olvidadas, rondas del Reinado, paloteos y romances. Algunos muchachos cantaban a los otros días alguna de las canciones que llevó Marazuela. Mujeres a quien nadie había oído cantar hace cuarenta años cantaron esa noche con el almirez (Patronato de Misiones Pedagógicas, 1934, p. 48).

A partir de 1933, coincidiendo con el segundo bienio del gobierno republicano (1933-1935), las Misiones Pedagógicas se vieron gravemente afectadas, principalmente por la falta de comprensión hacia la función que desempeñaban. Así, en 1935, se produjo una severa reducción de su asignación presupuestaria que mermó gran parte de sus actividades siendo el Coro uno de los servicios más perjudicados. Aun así, éste mantuvo sus valores esenciales y su sentido inicial: sana alegría, sencillez de formas y contenidos, dinamicidad y limpio acento folklórico (Patronato de Misiones Pedagógicas, 1935).

En el segundo volumen de las Memorias (1935) se informa que, a finales de 1934, este Servicio había efectuado ciento setenta y nueve

1 Agapito Marazuela (1891-1983): dulzainero, folklorista y musicólogo segoviano que colaboró con el Patronato de Misiones Pedagógicas, especialmente con los servicios de Música y Coro, asistiendo como misionero a diferentes localidades castellanas. 
salidas a localidades de las provincias de Madrid, Ávila, Segovia, Toledo, Ciudad Real, Cuenca, Guadalajara, Cáceres, Zamora, Valladolid y Salamanca. Los domingos, sus integrantes actuaban en Madrid y en las provincias limítrofes en un radio de acción aproximado de cien kilómetros, de manera que pudieran actuar y regresar a sus casas en el mismo día evitando, en la medida de lo posible, no perturbar sus obligaciones de estudiantes. En Navidad, Carnavales y fiestas de primavera y fin de curso el Coro hizo viajes de más largo recorrido con actuaciones continuadas. Esto les permitió llegar a otras regiones y municipios más alejados, destacando la actuación de Trujillo en el claustro gótico del monasterio de Guadalupe ante más de dos mil espectadores.

\section{El Servicio de Música del Patronato}

El Servicio de Música consistió en la cesión de un gramófono y una colección de discos de repertorio popular y clásico a algunas poblaciones, material que se utilizaría tanto en las escuelas como en sesiones dedicadas a la educación de adultos (ver imagen 3).

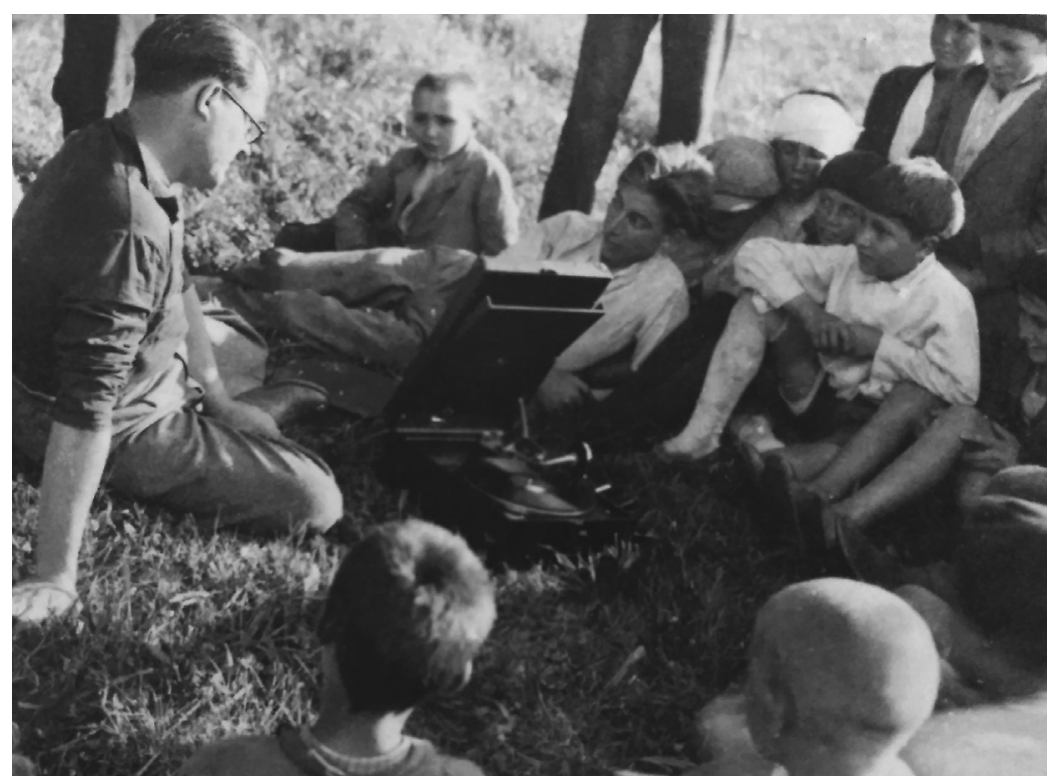

Imagen 3. Audición llevada a cabo con el material proporcionado por el Servicio de Música.

Fuente: Otero y García (2006, p. 428). 
Serían Eduardo Martínez Torner, Óscar Esplá y Pablo de Andrés los encargados de seleccionar el material musical y de diseñar los programas y las fichas informativas para las audiciones comentadas. Los maestros de las localidades seleccionadas serían los responsables de la custodia y el buen uso de este material y se encargarían de renovar periódicamente las colecciones de discos y de desplazarse a otras poblaciones cercanas para realizar sesiones musicales con los niños y adultos de esos lugares (López García, 2015).

Las colecciones de discos comprendían obras de canto gregoriano, lírica regional española, zarzuela, las grabaciones del Coro de las Misiones y una selección de obras de compositores españoles como Bretón, Chapí, Falla, Albéniz, Esplá, García Lorca o Turina y de compositores extranjeros como Bach, Beethoven, Haendel, Mozart, Mendelssohn, Schubert, Strauss, Debussy, Brahms, Saint Säens, Borodin, Mussorgski, Rimsky Korsakoff, Grieg, Dukas, Puccini, Ravel, Weber, Chopin, Lyszt, Wagner, Rossini, Berlioz, Gounod, Verdi, Franck o Stravinski.

En el resumen de los trabajos realizados en 1934 se informa que había 66 gramófonos repartidos y un total de 2135 discos (Pliego, 2006).

Pliego (2006) transcribe la reseña de la separata del primer número de la revista Residencia (1933) en la que se resume la labor del Servicio de Música en los siguientes términos:

Además de las bibliotecas, el Patronato deja en los pueblos visitados por sus misioneros gramófonos y discos seleccionados, para lo cual ha reunido interesantes colecciones integradas por música de los grandes compositores [...] Como la música regional es la que se halla más cerca del pueblo, resulta natural la preferencia que respecto a ella se advierte en casi todos los lugares donde el Patronato tiene ocasión de actuar. El éxito favorable del ensayo queda atestiguado por algunas de las noticias recibidas de los pueblos:

"El aparato ha estado dos veces en todas las aldeas de este valle, permaneciendo cada vez quince días en cada una de ellas. En la primera vuelta las audiciones fueron casi diarias y después todos los días festivos. Los oyentes no han sido nunca menos de ciento, y, a veces, hasta trescientos".

"Rogamos cambien los discos, dejando aquí por lo mucho que gustan La danza macabra, La Dolores y La danza de Anitra". 
"No sólo hemos procurado que fuese conocido por los niños de este pueblo, sino que hemos organizado paseos y excursiones a varias aldeas distantes cuatro y cinco kilómetros, llevando a sus escuelas un poco de alegría. En estas excursiones se ha hecho alguna vez música en pleno campo, causando la delicia de niños y niñas".

"Los discos de música selecta no son comprendidos al principio por los oyentes; pero, al repetir las audiciones, son escuchados con delectación".

Son, de nuevo, las Memorias del Patronato las que nos informan del uso del material del Servicio de Música (gramófonos y discos de pizarra) en sesiones programadas y realizadas tanto en la escuela como fuera de ella (ayuntamientos, locales municipales, parajes naturales), así como de la programación de audiciones con adultos especialmente en fines de semana. Además, las noticias aportadas por los encargados del Servicio muestran la preferencia de los lugareños por la música popular y los cantos regionales que, en numerosas ocasiones, serían utilizados como gancho para aumentar el número de asistentes y como paso previo a las audiciones de música clásica.

Aunque los Servicios y los programas de actividades de las Misiones no recogían otras experiencias relacionadas con la música, disponemos de algunos documentos que dan testimonio de la presencia y la práctica de danzas y bailes populares. De hecho, Canes (1993) nos recuerda que era normal interpretar este tipo de danzas y bailes como reclamo y comienzo de las actividades propias de la misión. En esta misma línea, las Memorias recogen el diario de las actividades llevadas a cabo en el municipio de Castropol (Asturias), en el que podemos leer: "Las canciones tradicionales y los bailes de la tierra han caído en completo olvido. Pero no bien se los recuerda con cierta insistencia, parecen surgir de todas partes y vuelven a popularizarse". Y sigue diciendo: "Los bailes de la comarca se revivieron en la fiesta del volumen 3000 (octubre, 1933), a saber, el cariado, el cacheteado y el pis-pis o valsuviana, se han vuelto a bailar por las aldeas este invierno y constituyeron la atracción de bastantes bailes celebrados recientemente" (Patronato de Misiones Pedagógicas, 1934, p. 190). 
Por otro lado, una de las fuentes primarias más importantes de que disponemos es el libro El folklore en la escuela (1936), de Eduardo Martínez Torner, en el que el autor recoge canciones, juegos, danzas e indicaciones coreográficas puestas en práctica en las diferentes misiones. Este material, junto con algunas fotografías publicadas en el catálogo de la exposición, da buena fe de la presencia de las danzas y bailes populares como parte de las actividades desarrolladas en las localidades misionadas (ver imagen 4).

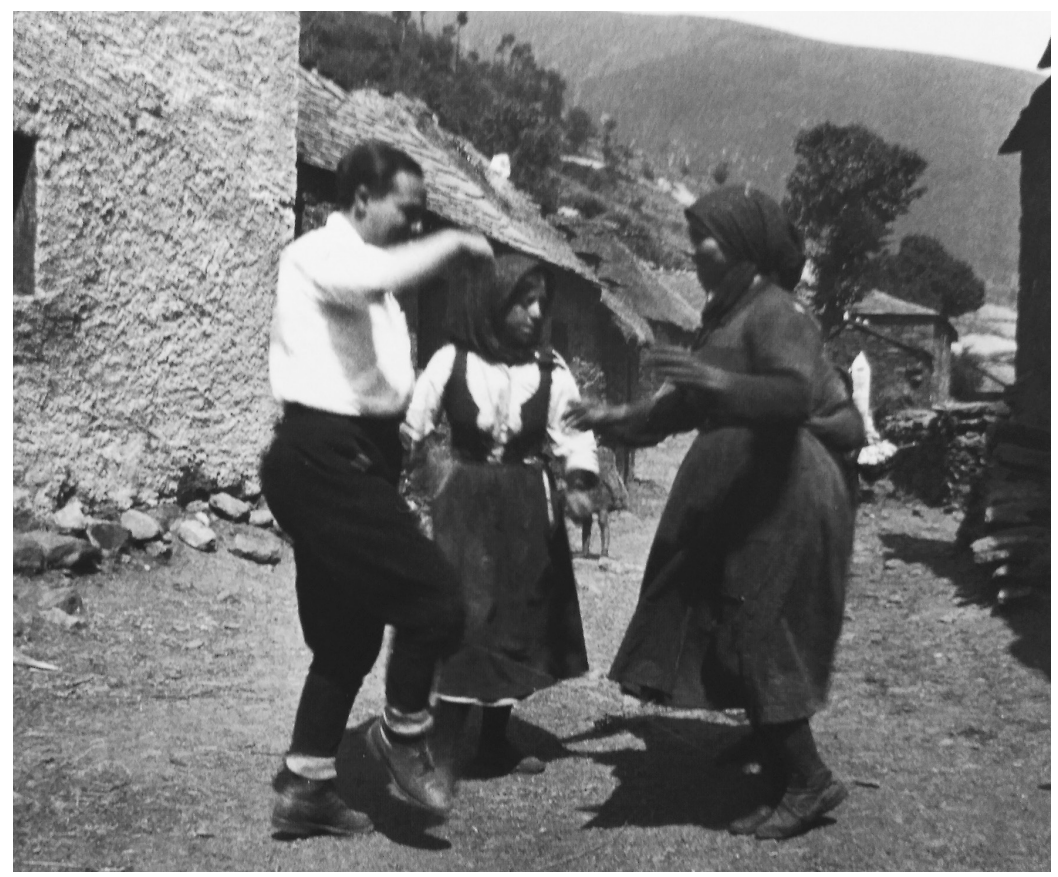

Imagen 4. Luis Vega (Inspector de Educación) bailando con dos aldeanas.

Fuente: Otero y García (2006, p. 112).

Finalmente, hay que destacar que el Patronato se encargó de programar y celebrar varios cursos de formación para maestros en los que se impartieron lecciones de música, se realizaron audiciones comentadas y se enseñaron canciones populares, todo ello con el objetivo de preparar a los docentes para acercar el hecho musical a los alumnos de sus escuelas rurales así como a los adultos que asistían a las sesiones de música programadas. 


\section{Conclusiones}

No cabe duda de que el Patronato de Misiones Pedagógicas se esforzó por llevar a cabo un gran proyecto de musicalización nacional cuyo objetivo principal consistió en acercar la música y la cultura musical a todos los rincones de la geografía española intentando disminuir, en lo posible, las enormes diferencias existentes entre el mundo rural y el mundo urbano, programando una serie de actividades musicales que se pusieron en práctica en las zonas rurales más desfavorecidas (ver tabla 1). Esto supuso un claro intervencionismo estatal en pro del desarrollo musical de la población, por primera vez en la historia de la educación musical española, que ponía de manifiesto el profundo interés del gobierno republicano por acercar el hecho musical al pueblo y por potenciar las manifestaciones artísticas a lo largo y ancho del país, obviando las dificultades económicas y la escasez de recursos humanos en que estaba sumido.

Las Misiones lograron estimular, por un lado, la popularización de la música tradicional española devolviendo a la memoria colectiva piezas olvidadas y, por otro, el oído y el gusto musicales de la población rural que, partiendo del folklore nacional y tras una insistente labor de audiciones comentadas, terminó valorando y disfrutando la música culta de calidad (Sánchez de Andrés, 2006).

Sin embargo, los cambios políticos producidos entre 1933 y 1935 cercenaron, en cierta medida, los avances conseguidos en el terreno educativo lo que perjudicó a las Misiones Pedagógicas que se vieron afectadas, principalmente, por la falta de comprensión hacia la función que desempeñaban. Así, en 1935 se redujo su asignación presupuestaria y, como consecuencia más directa, su actividad.

La Guerra Civil española (1936-1939) y el posterior período político surgido como consecuencia de la misma terminaron definitivamente con su tarea pedagógica fundamentada en la democratización de la cultura y en el acceso a la misma como derecho de todo ciudadano. 
Tabla 1. Localidades donde estaba establecido el Servicio de Música a finales de 1934

\begin{tabular}{|l|l|}
\hline Provincia & \multicolumn{2}{|c|}{ Localidad } \\
\hline Ávila & Burgohondo \\
\hline Álava & Narvaja, Peñacerrada \\
\hline Burgos & Bahabón de Esgueva, Milagros, Arandilla y Treviño \\
\hline Cádiz & Villaluenga del Rosario y Benamahoma \\
\hline Cáceres & Navas del Madroño \\
\hline Cuenca & Beteta, Chillarón, Garaballa y Valdecabras \\
\hline Guadalajara & $\begin{array}{l}\text { Campillo de Ranas, Condemios de Abajo, Colmenar de } \\
\text { la Sierra y Valdepeñas de la Sierra }\end{array}$ \\
\hline Huesca & Huesca y Bonansa \\
\hline León & La Baña, León, Pombriego y Soto de Valdeón \\
\hline Lérida & Lérida y Lés \\
\hline Madrid & $\begin{array}{l}\text { Alameda del Valle, Horcajo, Horcajo de la Sierra y } \\
\text { Montejo de la Sierra }\end{array}$ \\
\hline Oviedo & $\begin{array}{l}\text { Oviedo, Alevia, Besullo, Cangas del Narcea, Puentecastro, } \\
\text { La Moñeca y Castropol }\end{array}$ \\
\hline Palencia & Palencia \\
\hline Soria & Alcubilla de Avellaneda \\
\hline Segovia & $\begin{array}{l}\text { Segovia, Ayllón, Funtepelayo, La Cuesta, Cuéllar, Fuente } \\
\text { el Olmo de Iscar, Turégano y Vegas de Matute }\end{array}$ \\
\hline Toledo & Navalcán, Pelahustán y Navas del Madroño \\
\hline Valencia & $\begin{array}{l}\text { Valencia, Jaraguas, Collado Alpuente, Corcolilla de } \\
\text { Alpuente, Cuevarruz Alpuente y Puebla de San Miguel }\end{array}$ \\
\hline Vizcaya & Rioseco de Carranza \\
\hline Málaga & Ronda, Lagos y Málaga \\
\hline Ciudad Real & Arroba de los Montes y Ciudad Real \\
\hline Murcia & Cartagena \\
\hline Badajoz & Castilblanco, Herrera del Duque \\
\hline Logroño & Treguajantes, Hornillos de Gameros \\
\hline Zamora & San Martín de Catañeda \\
\hline
\end{tabular}

Fuente: elaboración propia a partir de las Memorias del Patronato de Misiones Pedagógicas (1934). 
Esto pone en evidencia, una vez más, las dificultades que en materia educativa y cultural vienen sucediendo a lo largo de la historia más reciente de España debidas, fundamentalmente, a las diferentes tendencias ideológicas que alcanzan el poder político del país. Desde nuestro punto de vista, el caso del Patronato de Misiones Pedagógicas es especialmente llamativo, ya que el gobierno surgido tras las elecciones de finales de 1933 (segundo bienio republicano) no dudó en poner en entredicho todas aquellas medidas que impulsaban su continuidad sin tener en cuenta los resultados obtenidos y la opinión tanto de colaboradores como de misionados, quedando definitivamente paralizadas con la llegada del régimen dictatorial de 1936, a pesar de que, como afirma con rotundidad la Sociedad Estatal de Conmemoraciones Culturales (2007), la labor desarrollada por esta institución ha sido una de las experiencias culturales, educativas y sociales más originales e innovadoras emprendidas por un gobierno europeo en todo el siglo $\mathrm{XX} \mathbf{C}$ 


\section{Referencias}

Ayala, I. M. (2013). Música y municipio: marco normativo y administración de las bandas civiles en España (1931-1986). Estudio en la provincia de Jaén. Granada: Editorial de la Universidad de Granada.

Canes, F. (1993). Las misiones pedagógicas: educación y tiempo libre en la Segunda República. Revista Complutense de Educación, 1(4), 147-168. Recuperado de https://bit.ly/2K2zVj7.

Calvo, A. y León, J. A. (2011). Historia de la danza contemporánea en España. Arte y Movimiento, 4, 17-30. Recuperado de https://bit. ly/2HUYY2t

Casares, E (1999). Diccionario de la música española e hispanoamericana. Madrid: Sociedad General de Autores y Editores.

Decreto de 29 de mayo. (1931). Creando, dependiente del Ministerio de Instrucción Pública y Bellas Artes, un Patronato de Misiones pedagógicas encargado de difundir la cultura general, la moderna orientación docente y la educación ciudadana, en aldeas, villas y lugares, con especial atención a los intereses espirituales de la población rural. Madrid: Gaceta de Madrid, 150, 30 de mayo de 1931 (pp. 1033-1034).

Dennis, N. (2011). Ramón Gaya y el Museo del Pueblo de las Misiones Pedagógicas. Escritura e Imagen, 7, 15-26. Recuperado de https://bit. ly/2JSHmpF

Gil, J. (2007). La música en el siglo XX hasta la Segunda Guerra Mundial (Iv): la música en España. En M. Serrano y J. Gil (Coords.), Música: temario cuerpo de profesores de Educación Secundaria (pp. 387-407). Sevilla: MAD.

Gimeno, J. (2011). Esbozo de una utopía: las Misiones Pedagógicas de la II República española (1931-1939). Revista F@ro, 13, 160-178. Recuperado de https://bit.ly/2MyZWof

Hontañón, B. y Pericacho, F. J. (2015). Las misiones pedagógicas de la Segunda República y la dictadura: naturaleza, evolución y problemática. Coloquio de Historia de la Educación: Arte, Literatura y Educación, 18(1), 186-197. Recuperado de https://bit.ly/2JI6y65

Puelles, M. (1991). El sistema educativo republicano: un proyecto frustrado. Historia Contemporánea, 6, 159-171. Disponible en https://bit.ly/2li7orP

López García, N. J. (2015). Necesidades profesionales del profesorado especialista de música de los centros de primaria de Castilla-La Mancha (Tesis doctoral). Universidad de Málaga, España. 
Marco, T. (1998). Historia de la música española. Vol. 6. Siglo XX. Madrid: Alianza Editorial.

Martín Ruano, S. (2015). El paso de las misiones pedagógicas por Extremadura. Revista de Estudios Extremeños, Número Extraordinario, 377-398. Recuperado de https://bit.ly/2JVVPBi

Martínez Torner, E. (1936). El folklore en la escuela. Madrid: Publicaciones de la Revista de Pedagogía.

Moreno, P. L. (2017). Imágenes e historia de la educación popular: representaciones fotográficas de las misiones pedagógicas en la Región de Murcia. Historia y Memoria de la Educación. Sociedad Española de Historia de la Educación, 5, 73-155. Recuperado de https://bit. ly/2LXTztQ

Ocaña, A. (2006). Identidad y ciclos de desarrollo profesional de los maestros y maestras de educación musical. Granada: Servicio de Publicaciones de la Universidad de Granada.

Otero, E. y García, M. (Eds). (2006). Las Misiones Pedagógicas. 19311936. Madrid: Sociedad Estatal de Conmemoraciones Cuturales Residencia de Estudiantes.

Patronato de Misiones Pedagógicas. (1934). Memorias. Septiembre de 1931 Diciembre de 1933. Madrid: S. Aguirre.

Patronato de Misiones Pedagógicas (1935). Memoria de la misión pedagógicosocial en Sanabria (Zamora). Resumen de trabajos realizados en el año 1934. Madrid: S. Aguirre.

Pliego, V. (2006). El servicio de música: Eduardo Martínez Torner y Pablo de Andrés Cobos. En E. Otero y M. García (Eds.), Las Misiones Pedagógicas. 1931-1936 (pp. 414-435). Madrid: Sociedad Estatal de Conmemoraciones Culturales - Residencia de Estudiantes.

Real Decreto de 10 de enero de 1907. (1907). Creando una Junta para el fomento de la educación nacional. Madrid: Gaceta de Madrid, 14, enero 14 de 1907 (pp. 157-158).

Sánchez de Andrés, L. (2006). Canciones interpretadas por los coros de las Misiones Pedagógicas. Armonizadas por Eduardo Martínez Torner [Notas al CD]. En E. Otero y M. García (Eds.), Las Misiones Pedagógicas. 1931-1936. Madrid: Sociedad Estatal de Conmemoraciones Culturales - Residencia de Estudiantes.

Sociedad Estatal de Conmemoraciones Culturales. (2007). Las Misiones Pedagógicas. 1931-1936. Madrid: Fundación Giner de los Ríos.

Tapia, G. (2006). Las Misiones Pedagógicas [Documental en DVD]. España: SECC-TVE. Acacia Films-Malvarrosa Media. 


\section{Bibliografía}

Asensio, S. (2011). Eduardo Martínez Torner y la Junta para Ampliación de Estudios en España. Revista Arbor, 751(187), 857-874. Recuperado de https://bit.ly/2LXUJoS

Bardin, L. (2002). Análisis de contenido. Tres Cantos (Madrid): Akal.

Dulzaides, M. E. y Molina, A. M. (2004). Análisis documental y de información: dos componentes de un mismo proceso. ACIMED, 12(2), 1-5. Recuperado de https://bit.ly/1QivjOW

López Casanova, M. B. (2002). La política educativo-musical en España durante la Segunda República. Música y Educación. Revista Trimestral de Pedagogía Musical, 50, 15-25. Recuperado de https://bit. ly/2MyGvMH

Martín, M. (2002). Las misiones pedagógicas en Salamanca (1931-1936). Aula, 14, 155-178. Recuperado de https://bit.ly/2JMpG2P

Martínez de Carnero, F. (2015). La Institución Libre de Enseñanza y las Misiones Pedagógicas: cultura difusa de misioneros y misionados. En M. R. Sánchez (Coord.), La construcción de la identidad pedagógica española: entre la Institución Libre de Enseñanza y las Escuelas del Ave María (pp. 139-148). Madrid: Síntesis.

Sánchez Llamas, F. J. (1994). Dos visiones de educación popular. El Patronato de Misiones Pedagógicas y las Cátedras Ambulantes. Isla de Arriarán: Revista Cultural y Científica, 4, 129-140. Recuperado de https://bit.ly/2t2JswO 